\title{
The Impact of Ethnic-Immigrant Status and Obesity-Related Risk Factors on Behavioral Problems among US Children and Adolescents
}

\author{
Gopal K. Singh and Stella M. Yu \\ Maternal and Child Health Bureau, Health Resources and Services Administration, US Department of Health and Human Services, \\ Room 18-41, 5600 Fishers Lane, Rockville, MD 20857, USA \\ Correspondence should be addressed to Gopal K. Singh; gsingh@hrsa.gov
}

Received 30 October 2012; Accepted 12 December 2012

Academic Editors: G. Mastrangelo and J. Oei

Copyright (C) 2012 G. K. Singh and S. M. Yu. This is an open access article distributed under the Creative Commons Attribution License, which permits unrestricted use, distribution, and reproduction in any medium, provided the original work is properly cited.

\begin{abstract}
We examined the prevalence and correlates of parent-reported behavioral problems among immigrants and US-born children aged 6-17 years. The 2007 National Survey of Children's Health was used to develop an 11-item factor-based behavioral problems index (BPI) and a dichotomous serious behavioral problems (SBP) measure. Logistic and least-squares regression and disparity indices were used to analyze differentials. BPI scores varied from 92.3 for immigrant Asian children to $\geq 102.4$ for native Hispanic and Black children. The prevalence of SBP ranged from 2.9\% for immigrant Asian children to $17.0 \%$ for native Black children. Children in most ethnic-immigrant groups had higher adjusted levels of behavioral problems than immigrant Asian children. Native Hispanic children, native and immigrant White children, immigrant Black children, and native Asian children had $\geq 3.0$ times higher adjusted odds of SBP than immigrant Asian children. Lower socioeconomic status, obesity, physical inactivity, lack of sports participation, increased television viewing, and sleep disruption were associated with greater behavioral problems. Sociodemographic and behavioral factors accounted for $37.0 \%$ and $48.5 \%$ of ethnic-immigrant disparities in BPI and SBP, respectively. Immigrant children had fewer behavioral problems than native-born children. Policies aimed at modifying obesity-related behaviors and social environment may lead to improved behavioral/emotional health in both immigrant and native children.
\end{abstract}

\section{Introduction}

Behavioral and emotional problems in children have significant impacts on their health and wellbeing [1-4]. Children with emotional and behavioral problems are more likely to have poor academic performance, to repeat a grade in school, to face school suspension, and to develop behavioral and mental health problems in adulthood and are less likely to engage in social activities outside of school [1-4]. Evidence also suggests that emotional and behavioral problems in children have an adverse effect on their parents' mental health and subjective wellbeing and are associated with increased levels of parental and familial stress $[1,2,5]$.

A number of studies have analyzed gender, racial/ethnic, and socioeconomic variations in children's mental health and behavioral problems [3-9]. However, few studies have examined the impact of nativity/immigrant status, obesity, and obesity-related risk factors on behavioral outcomes among children [10-13]. Moreover, most previous studies on ethnic and social determinants have focused on either internalizing (depression, anxiety, and withdrawal) [3] or externalizing behaviors (aggression and antisocial behavior) [7], but few have examined determinants of problem behaviors more broadly capturing both internalizing and externalizing behaviors $[4,8-10]$. Furthermore, most studies of emotional/behavioral outcomes have focused either on young children $[3,7,8]$ or on adolescents $[9,10]$ but have generally not covered the entire school-age population of 6-to17 years old [4]. Additionally, most studies of obesity-related effects on children's mental health have used nonnationally representative samples [4].

The immigrant population in the United States has grown considerably in the last four decades. In 2011, there were 40.4 million immigrants in the United States, which indicates an 
increase of 30.8 million in the immigrant population since 1970 [14-19]. Immigrants currently account for $13.0 \%$ of the total US population $[15,19]$ increase in the immigrant child population has been even more rapid and substantial. The number of US children in immigrant families increased more than two-fold in the past two decades, from 8.2 million in 1990 to 17.5 million in 2011 [19, 20]. In 2011, 24.4\% of US children had at least one foreign-born parent $[19,20]$. Despite the rapid increase in the population, behavioral health disparities among immigrant children are not well studied. It is often hypothesized that children in immigrant families may be at greater risk for behavioral and emotional health problems than children of native- or US-born parents due to the stresses associated with immigration, acculturation, and their ethnic-minority status [10, 14].

Obesity-related behaviors are one possible mechanism through which ethnic and social factors might influence behavioral and mental health disparities in children [4, 11]. Assessing potential mental health effects of obesityrelated risks is important because the prevalence of childhood obesity and physical inactivity has risen markedly during the past three decades not only in the United States, but also in many other industrialized countries of the world $[21,22]$. Moreover, obesity-related behaviors are amenable to change through public policy and social interventions [2123]. To the extent that obesity-related risks negatively affect children's behavioral health, positive changes in these risk behaviors are expected to improve mental health outcomes in children [4].

To address the aforementioned gaps in behavioral health research, we used the 2007 National Survey of Children's Health (NSCH) to analyze the impact of ethnic-immigrant status and several obesity-related risk factors on childhood behavioral problems in the United States [24, 25]. In this study, we (1) estimate prevalence of behavioral problems among 62,804 children and adolescents aged $6-17$ by ethnicimmigrant status, obesity, physical activity, sedentary activities, sleep behavior, and other sociodemographic characteristics, (2) assess the effects of ethnic-immigrant status and obesity-related risk factors on childhood behavioral problems after adjusting for household-level and individuallevel socioeconomic and demographic characteristics, and (3) examine the extent to which behavioral health effects of obesity-related risk factors vary by the immigrant status.

\section{Methods}

The data for this study came from the 2007 NSCH [2426]. The survey was conducted by the Centers for Disease Control and Prevention's (CDC) National Center for Health Statistics (NCHS), with funding and direction from the Health Resources and Services Administration's Maternal and Child Health Bureau [24, 25]. Its purpose was to provide national and state-specific prevalence estimates for a variety of indicators of children health and wellbeing [24-26].

The survey was conducted by telephone between April 2007 and July $2008[25,26]$. It had a total sample size of 91,642 children under 18 years of age, including a sample of about 1800 children per state $[25,26]$. A random-digit-dial sample of households with children younger than 18 was selected from each of the 50 states and Washington, DC. One child was selected in each identified household to be the subject of the survey.

Interviews were conducted in English, Spanish, and four Asian languages. The respondent was the parent or guardian who knew most about the child's health status and health care. Consequently, all survey data were based on parental reports. The interview completion rate, measuring the percentage of completed interviews among known households with children, was $66.0 \%$ [26]. The overall response rate at the national level was $46.7 \%$ [26]. Substantive and methodological details of the survey are described elsewhere [24-26]. The NCHS Research Ethics Review Board approved all data collection procedures.

The dependent variable was measured by a composite behavioral problems index (BPI). Behavioral problems scales have been used previously and have been validated against emotional/behavioral and school outcomes among children [4, 27-29]. In our study, the BPI was constructed using principal components analysis of 11 items capturing parents' ratings of their children on a set of behaviors, including arguing, bullying, disrespect, not getting along with others, disobedience, irritability, lacking empathy and conflict resolution strategies, and feelings of worthlessness, depression, and detachment (Table 1) [4]. The factor loadings for the BPI varied from a low of 0.51 for "detachment" to a high 0.63 for "irritability." The BPI had a high reliability coefficient $($ alpha $=0.80)$. Higher scores on the BPI (mean $=100 ; \mathrm{SD}=$ 20) indicate higher levels of behavioral problems [4].

The validity of the BPI was assessed by comparing the item factor loadings for immigrants and natives and for major racial/ethnic groups. The factor loadings for the various ethnic and immigrant groups were generally similar in relative importance and the reliability coefficient of the BPI for each subgroup was high, exceeding 0.75. A binary variable of serious behavioral problems (SBP) was also defined based on the 90th percentile cutoff for the BPI scores. Such cutoffs have been used previously to identify children with serious behavioral problems [29]. To test the concurrent validity of the BPI, we estimated the magnitude of the association (the gamma statistic) between the dichotomous SBP variable and parent-reported diagnoses of depression ( 0.88 for both immigrants and natives), anxiety (0.82 for immigrants and 0.81 for natives), oppositional defiant disorder/conduct disorder (0.94 for immigrants and 0.93 for natives), and Attention Deficit Disorder (ADD) or Attention Deficit Hyperactive Disorder (ADHD) (0.72 for both immigrants and natives). The quartile distribution of the BPI was also highly correlated with the degree/severity of depression $(\gamma=0.83$ for immigrants and 0.81 for natives), anxiety ( 0.73 for immigrants and 0.69 for natives), conduct disorder ( 0.91 for immigrants and 0.89 for natives), and ADD/ADHD (0.56 for immigrants and 0.54 for natives). To test the predictive validity of the BPI, we examined its association with several child and parental health outcomes. Higher BPI levels were related with higher prevalence and risks of poor child health, school absence, and poor mental health, unhappiness, and higher 


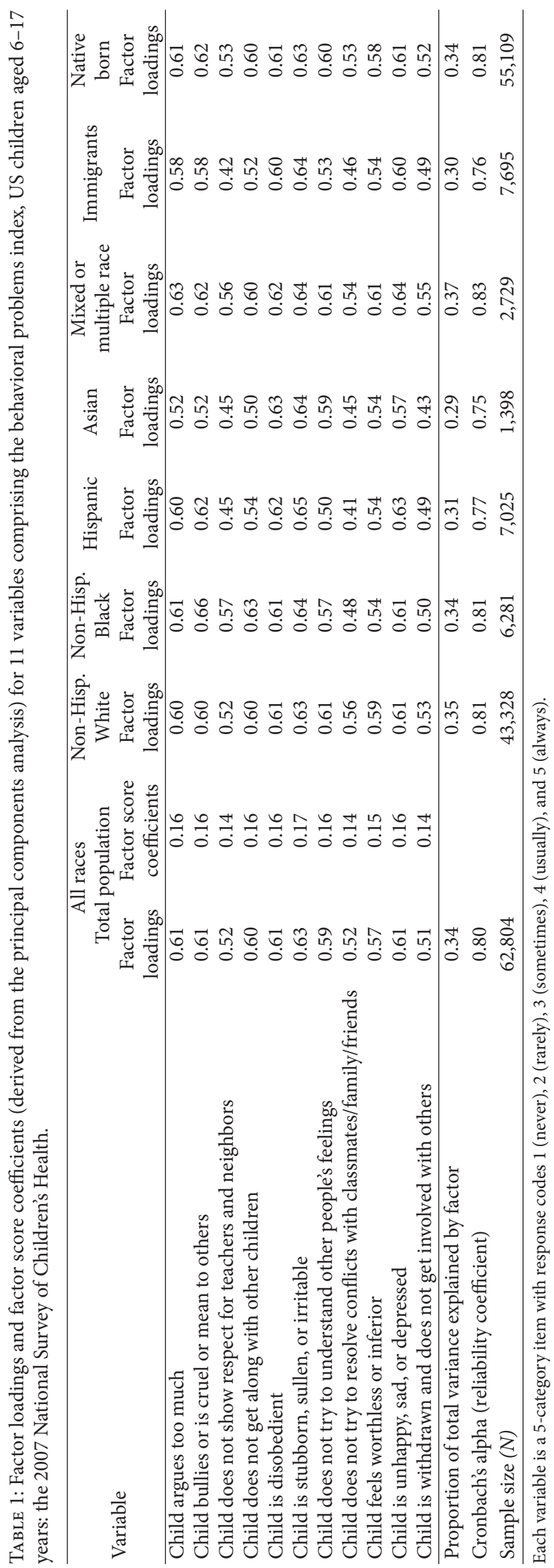


stress/aggravation levels among parents in both immigrant and native-born families (Table 2).

The primary covariates of interest were nativity/immigrant status, obesity/overweight status, and obesity-related risk factors. Immigrant status was defined according to parents' nativity status $[14,30,31]$. Immigrant children and adolescents were defined as those born to one or both immigrant parents. US-born children with both USborn parents were considered as the native-born [14, 30, 31]. Race/ethnicity was classified into 5 categories: nonHispanic whites, non-Hispanic blacks, Hispanics, Asians, and other (including American Indians/Alaska Natives, Hawaiian/Pacific Islanders, and mixed/multiple races). The joint variable of ethnic-immigrant status included 10 categories, with each of the 5 broad ethnic groups having two nativity categories. Acculturation was measured by the number of years that the foreign-born mother lived in the United States.

The BMI status consisted of three categories: overweight $(\mathrm{BMI}=85$ th to $<95$ th percentile), obese $(\mathrm{BMI}=\geq 95$ th percentile), and normal weight (BMI $<85$ th percentile). Obesity-related factors included television viewing time, physical activity, sports participation, and sleep duration. Television viewing was based on the question, "on an average school day, how many hours does the child usually watch TV, watch videos, or play video games?" The number of hours spent per day watching television was coded into four categories: $<1,1,2$, and $\geq 3$. Physical activity (PA) was based on the question, "During the past week, on how many days did the child exercise or participate in physical activity for at least 20 minutes that made him/her sweat and breathe hard, such as basketball, soccer, running, or similar aerobic activities?" The responses to the PA variable were coded as $0,1-2,3-4$, and $\geq 5$ days per week. Sport participation was a dichotomous variable derived from the question, "During the past 12 months, was the child on a sports team or did s/he take sports lessons after school or on weekends?" Sleep behavior was measured by the number of nights the child got adequate sleep during the week preceding the survey and was coded as $0,1-4$, and 5-7 nights per week [4].

Besides the above primary covariates, based on previous research, we used the following variables as covariates: child's age, gender, race/ethnicity, household composition, perceived neighborhood safety, and household poverty status (measured as a ratio of family income to the poverty threshold) $[1-5,11,13,27-29,32,33]$. These covariates were measured as shown in Tables 3-5.

Fewer than $2 \%$ of the observations had missing data on one or more of the behavioral items comprising the BPI, which was constructed for 62,804 children aged 6-17. Household income was imputed for $9 \%$ of the observations by using a multiple imputation technique [26]. For all other covariates, there were few missing cases, which were excluded from multivariable models, yielding an effective sample size of 60,787 for the fully adjusted covariate models.

The $\chi^{2}$ statistic was used to test the overall association between each covariate and behavioral problems. To estimate differentials in risks of SBP and mean BPI scores, we fitted two sets of logistic and least squares regression models. The first set of models present the unadjusted odds of serious behavioral problems or mean BPI associated with each covariate. The second set of models yield the adjusted effects of immigrant status after controlling for age, gender, race/ethnicity, household composition, neighborhood safety, poverty status, and obesity-related behaviors. A demographic model without the intervening obesity-related behaviors was also fitted, which yielded the underlying adjusted effects of ethnic-immigrant status and SES.

We used root mean square deviation (RMSD) as a new summary measure of behavioral health disparities among 10 ethnic-immigrant groups. The RMSD is similar to the square root of the variance, except that the average squared deviations are calculated using a "standard" estimate other than the sample mean. The RMSD is given by the formula

$$
\operatorname{RMSD}=\operatorname{SQRT}\left\{\frac{\sum_{i}\left(X_{r i}-X_{r l}\right)^{2}}{I}\right\},
$$

where $X_{r i}$ is the BPI score or SBP prevalence for the $i$ th group $(i=1,2, \ldots, 10), X_{r l}$ is the corresponding statistic for the "standard" group (total US population) or group with the lowest prevalence of behavioral problems (i.e., immigrant Asian children), and $I$ is the number of ethnic-immigrant groups (10) being compared.

While RMSD is a measure of absolute health disparity, the coefficient of variation $(\mathrm{CV})$ of the RMSD provides an estimate of relative disparity and is given by

$$
\mathrm{CV}(\mathrm{RMSD})=\left(\frac{\mathrm{RMSD}}{X_{r l}}\right) \times 100 ; \quad X_{r l}>0 .
$$

An additional measure of relative disparity, population attributable risk (PAR) indicating excess behavioral problems was also computed. We estimated interactions of obesityrelated risk factors with gender and immigrant status by running separate regression models for immigrant and native children and for male and female children. The results of stratified models are briefly discussed but are not shown to conserve space. To account for the complex sample design of the NSCH, SUDAAN software was used to conduct logistic and least squares analyses and to estimate means, prevalence estimates, predicted marginals, and corresponding standard errors [34].

\section{Results}

The 10 ethnic-immigrant groups varied substantially in their sociodemographic and behavioral characteristics (Table 3 ). Immigrant children in each racial/ethnic group were more likely to live in two-parent households than native-born children. Approximately $40 \%$ of immigrant Hispanic children or parents lived below the poverty line, compared with $6.4 \%$ of white immigrants and $5.7 \%$ of native-born Asians. Immigrant white and Black children had higher household socioeconomic status (SES) than their native-born counterparts, while the converse was true for Hispanic children. More than half of all immigrant children lived in non-English-speaking 


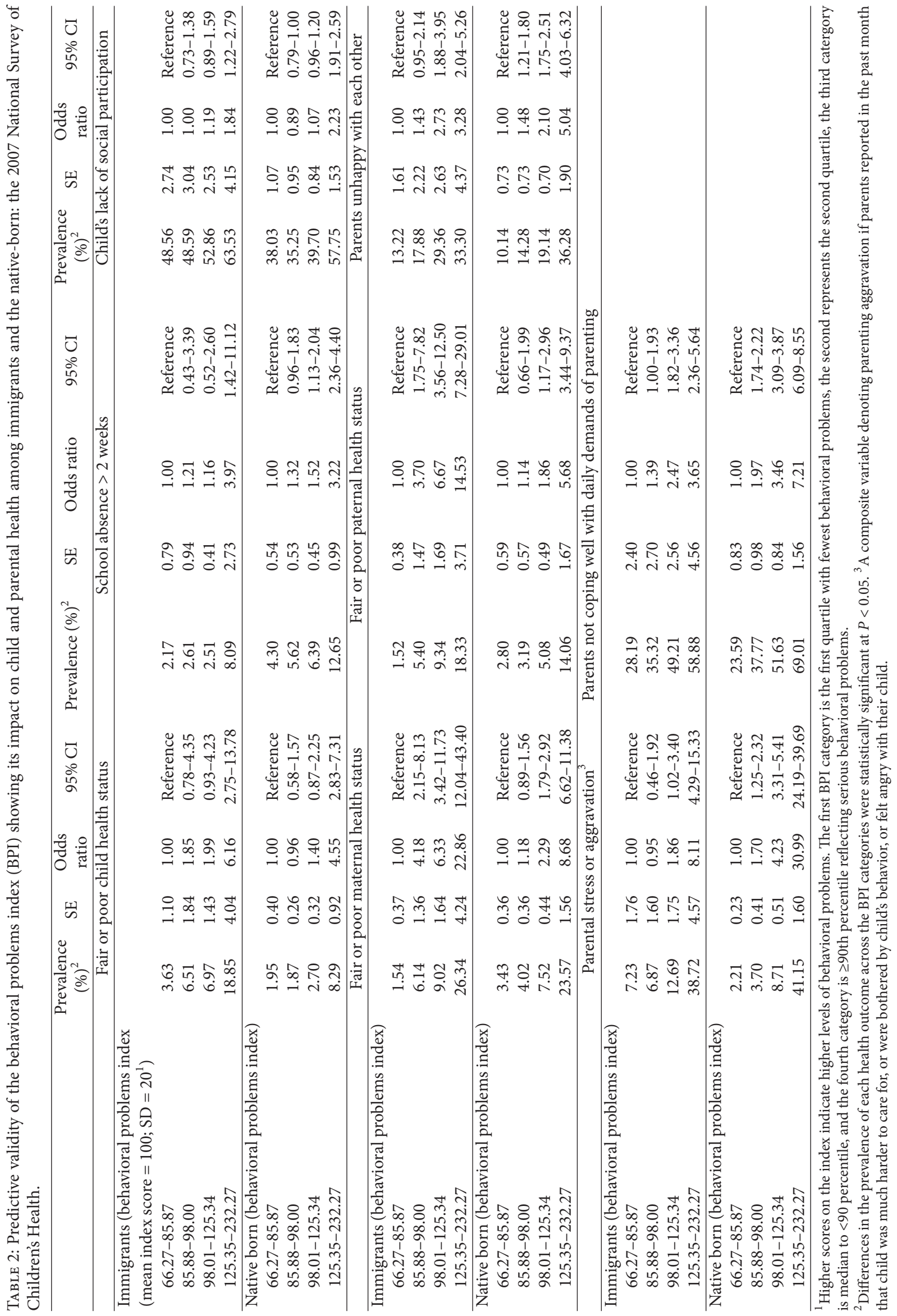




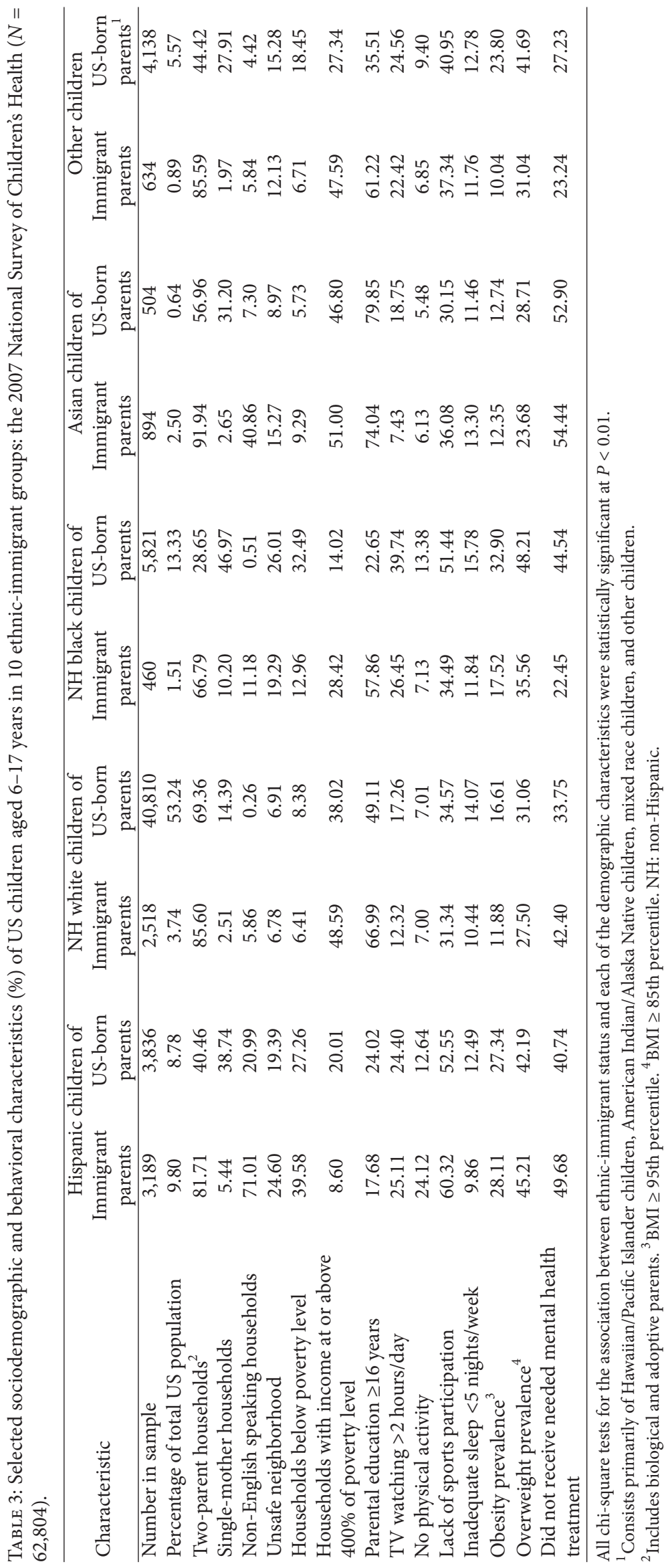


households, compared with $2.9 \%$ of native-born children. Approximately one-fourth of native-born Black children and immigrant Hispanic children lived in unsafe neighborhoods, compared with $6.8 \%$ of immigrant white children. Immigrant children were more likely to be physically inactive than native-born children, with immigrant Hispanic children twice as likely to be inactive as native-born Hispanic children. Television viewing and sleep problems were less common among immigrant children than native children. Immigrant children had lower obesity and overweight prevalence than native children. Obesity prevalence varied from a low of $11.9 \%$ for immigrant white children to a high of $32.9 \%$ for native-born Black children (Table 3). Immigrant children were significantly less likely to have access to mental health services than native-born children (44.5\% versus $36.2 \%)$.

In $2007,11.8 \%$ of US children aged $6-17$ were estimated to have SBP, with the prevalence being 30\% higher among males than females (Table 4). The overall prevalence of SBP in immigrant children was $10.6 \%$, not significantly different from the prevalence of $12.0 \%$ in native children. Mean BPI level was 98.1 for immigrant children, significantly lower than the mean score of 101.5 for native children. Nativity differentials in mean BPI were significant for both males and females $(P=0.0003)$; the mean BPI scores were $99.3,102.7$, 96.9 , and 100.2 for immigrant males, native males, immigrant females, and native females, respectively. Immigrant patterns in mean BPI score and SBP prevalence varied by ethnicity. The BPI score varied from a low of 92.3 for immigrant Asian children to 102.4 or higher for native Hispanic and Black children. Prevalence of SBP ranged from $2.9 \%$ for immigrant Asian children to $17.0 \%$ for native Black children (Table 4). After adjusting for sociodemographic and obesity-related risk factors, children in most ethnic-immigrant groups had higher levels of behavioral problems than immigrant Asian children (Table 5). The mean BPI scores for native Hispanic children, native and immigrant white children, and native Asian children were at least 5.3 points higher than those for immigrant Asian children. Native Hispanic children, native and immigrant white children, immigrant Black children, and native Asian children had at least 3.0 times higher adjusted odds of experiencing SBP than immigrant Asian children (Table 5).

Children's risk of SBP and mean levels of BPI increased significantly in relation to mother's duration of residence in the United States (Table 5). Immigrant children whose mothers had immigrated to the US in the past 5 years scored 3.7 points lower on the mean BPI and experienced $54 \%$ lower odds of SBP than children of US-born parents (Table 5).

About 23\% of children who did not engage in any vigorous PA experienced SBP, compared to $8.8 \%$ of children who exercised at least five days/week. Children with no PA had 2.0 times higher adjusted odds of SBP than physically active children, with mean BPI scores increasing in relation to lower PA levels (Table 5). Children who did not participate in sports had $64 \%$ higher odds of SBP than children who did participate. Children who watched television $>2$ hours/day had $65 \%$ higher adjusted odds of SBP, with mean levels of behavioral problems increasing in accordance with higher amounts of television viewing. Sleep duration was strongly and inversely associated with behavioral problems in children. Children experiencing inadequate sleep during the entire week had 3.2 times higher odds of SBP than children who did not experience any sleep problems during the week. The adjusted mean BPI scores among children increased consistently in relation to the frequency of sleep problems (Table 5). Obese children had significantly higher BPI levels than normal-weight children (Table 4). However, obesity or overweight status did not have a statistically significant effect on childhood behavioral problems after adjusting for sociodemographic and behavioral covariates.

About 20\% of children in unsafe neighborhoods experienced SBP, compared with $10.5 \%$ of children in safe neighborhoods. After adjusting for covariates, children in unsafe neighborhoods had $47 \%$ higher odds of SBP and 3.7 higher mean BPI than children living in safe neighborhoods. The impact of household income on children's behavioral problems was large. Nearly $21 \%$ of poor children experienced SBP, compared with $6.6 \%$ of affluent children (Table 4). After adjusting for the covariates, children living below the poverty line had 2.1 times higher odds of SBP and 7.8 points lower mean BPI than children whose family income exceeded $400 \%$ of the poverty threshold (Table 5). Children in stepfamily and single-mother households, respectively, had 2.0 and 1.6 times higher odds of SBP than children in two-biological-parent households even after adjusting for sociodemographic and behavioral characteristics (Table 5). All covariates including sociodemographic characteristics and obesity-related risk factors together accounted for $10.5 \%$ of the variance in the BPI (Table 6).

Interactions of gender with immigrant status, SES, and obesity-related behaviors were not statistically significant. Ethnic-immigrant and obesity-related behavioral patterns in BPI and SBP were generally similar for males and females. Similarly, socioeconomic and behavioral patterns in SBP and BPI were similar for immigrants and natives, with lower SES, unsafe neighborhoods, single-mother and stepfamilyhouseholds, physical inactivity, lack of sports participation, and higher levels of screen time and sleep disruption being associated with greater behavioral problems in both immigrant and native children.

\section{Discussion}

Using data from a large, nationally representative survey in the United States, we found substantial differentials in children's behavioral/emotional problems according to their ethnic-immigrant status. Overall, immigrant children were not more likely to have serious behavioral problems than native children, contrary to the commonly believed notion in the literature $[10,14]$. In fact, mean levels of behavioral problems were significantly lower in immigrant children than in native children. Immigrant Asian and Hispanic children had lower BPI levels than their native-born counterparts of equivalent socioeconomic and behavioral background. However, in keeping with the acculturation hypothesis, behavioral health problems among children from immigrant families seem to increase with increasing duration of residence in the United States [30, 31]. Moreover, their behavioral health 
TABLE 4: Mean behavioral problems index values and prevalence and unadjusted odds of serious behavioral problems according to ethnicimmigrant status and sociodemographic and behavioral characteristics, US children aged 6-17 years: the 2007 National Survey of Children's Health $(N=62,804)$.

\begin{tabular}{|c|c|c|c|c|c|c|c|}
\hline \multirow[b]{2}{*}{ Covariate } & \multicolumn{3}{|c|}{ Behavioral problems index ${ }^{1}$} & \multicolumn{4}{|c|}{ Serious behavioral problem $^{2}$} \\
\hline & Mean & SE & $P$ value & $\begin{array}{c}\text { Weighted } \\
\text { prevalence } \\
(\%)^{3}\end{array}$ & SE & $\begin{array}{c}\text { Unadjusted } \\
\text { OR }\end{array}$ & $\begin{array}{c}95 \text {-percent } \\
\text { confidence } \\
\text { interval }\end{array}$ \\
\hline Total population & 100.0 & 0.22 & & 11.76 & 0.34 & & \\
\hline \multicolumn{8}{|l|}{ Age (years) } \\
\hline $6-9$ & 100.4 & 0.36 & Reference & 9.79 & 0.53 & 1.00 & Reference \\
\hline $10-11$ & 100.5 & 0.57 & 0.865 & 11.53 & 0.88 & 1.20 & $0.98-1.48$ \\
\hline $12-14$ & 101.4 & 0.43 & 0.074 & 12.50 & 0.63 & 1.32 & $1.12-1.55$ \\
\hline $15-17$ & 101.1 & 0.47 & 0.267 & 13.67 & 0.74 & 1.46 & $1.23-1.73$ \\
\hline \multicolumn{8}{|l|}{ Gender } \\
\hline Male & 102.0 & 0.31 & $<0.001$ & 13.26 & 0.50 & 1.35 & $1.19-1.53$ \\
\hline Female & 99.6 & 0.32 & Reference & 10.19 & 0.45 & 1.00 & Reference \\
\hline \multicolumn{8}{|l|}{ Ethnic-immigrant status } \\
\hline Hispanic children of immigrant parents & 99.4 & 0.99 & $<0.001$ & 13.21 & 1.55 & 5.05 & $2.48-10.31$ \\
\hline Hispanic children of US-born parents & 102.4 & 1.03 & $<0.001$ & 14.26 & 1.55 & 5.52 & $2.72-11.19$ \\
\hline White children of immigrant parents & 99.2 & 0.89 & $<0.001$ & 8.74 & 1.16 & 3.18 & $1.54-6.53$ \\
\hline White children of US-born parents & 100.9 & 0.24 & $<0.001$ & 10.13 & 0.37 & 3.74 & $1.92-7.29$ \\
\hline Black children of immigrant parents & 98.4 & 2.18 & 0.012 & 12.17 & 3.27 & 4.60 & $1.88-11.23$ \\
\hline Black children of US-born parents & 102.6 & 0.68 & $<0.001$ & 16.95 & 1.00 & 6.77 & $3.44-13.32$ \\
\hline Asian children of immigrant parents & 92.3 & 1.10 & Reference & 2.93 & 0.96 & 1.00 & Reference \\
\hline Asian children of US-born parents & 99.8 & 2.41 & 0.004 & 9.63 & 3.60 & 3.53 & $1.24-10.07$ \\
\hline Other children of immigrant parents & 96.2 & 2.13 & 0.104 & 8.33 & 1.96 & 3.02 & $1.31-6.93$ \\
\hline Other children of US-born parents & 103.4 & 0.82 & $<0.001$ & 15.08 & 1.56 & 5.89 & $2.91-11.91$ \\
\hline \multicolumn{8}{|l|}{ Mother's duration of residence in the US (years) } \\
\hline$<5$ & 98.7 & 2.05 & 0.225 & 9.41 & 2.88 & 0.81 & $0.41-1.57$ \\
\hline $5-9$ & 99.0 & 1.48 & 0.147 & 13.19 & 3.10 & 1.18 & $0.69-2.02$ \\
\hline $10-14$ & 97.2 & 1.53 & 0.009 & 10.95 & 2.31 & 0.95 & $0.60-1.53$ \\
\hline $15+$ & 99.1 & 0.88 & 0.021 & 11.19 & 1.28 & 0.98 & $0.75-1.27$ \\
\hline US born & 101.2 & 0.24 & Reference & 11.41 & 0.36 & 1.00 & Reference \\
\hline \multicolumn{8}{|l|}{ Child's race/ethnicity } \\
\hline Non-Hispanic White & 100.8 & 0.23 & $<0.001$ & 10.04 & 0.36 & 2.49 & $1.48-4.19$ \\
\hline Non-Hispanic Black & 102.2 & 0.65 & $<0.001$ & 16.46 & 0.96 & 4.40 & $2.58-7.50$ \\
\hline Hispanic & 100.8 & 0.71 & $<0.001$ & 13.71 & 1.10 & 3.54 & $2.05-6.12$ \\
\hline American Indian/Alaska native & 102.7 & 1.45 & $<0.001$ & 13.76 & 2.36 & 3.56 & $1.86-6.79$ \\
\hline Asian & 93.8 & 1.05 & Reference & 4.29 & 1.08 & 1.00 & Reference \\
\hline Hawaiian/Pacific Islander & 99.4 & 3.02 & 0.080 & 14.56 & 4.35 & 3.80 & $1.61-8.97$ \\
\hline Non-Hispanic mixed race & 102.7 & 1.06 & $<0.001$ & 13.59 & 1.54 & 3.51 & $1.97-6.24$ \\
\hline Other & 102.2 & 1.81 & $<0.001$ & 15.66 & 4.03 & 4.14 & $1.88-9.13$ \\
\hline \multicolumn{8}{|l|}{ Household composition } \\
\hline Two-parent biological & 98.4 & 0.26 & Reference & 8.04 & 0.36 & 1.00 & Reference \\
\hline Two-parent stepfamily & 105.3 & 0.74 & $<0.001$ & 17.78 & 1.27 & 2.47 & $2.03-3.01$ \\
\hline Single mother & 105.3 & 0.54 & $<0.001$ & 18.45 & 0.94 & 2.59 & $2.22-3.02$ \\
\hline Other family type & 103.3 & 0.79 & $<0.001$ & 16.78 & 1.22 & 2.31 & $1.90-2.81$ \\
\hline \multicolumn{8}{|c|}{$\begin{array}{l}\text { Household poverty status (ratio of family income to } \\
\text { poverty threshold) }\end{array}$} \\
\hline$<100 \%$ & 105.7 & 0.68 & $<0.001$ & 20.73 & 1.10 & 3.73 & $3.10-4.49$ \\
\hline $100-199 \%$ & 102.2 & 0.59 & $<0.001$ & 14.87 & 0.92 & 2.49 & $2.06-3.02$ \\
\hline $200-399 \%$ & 100.3 & 0.38 & $<0.001$ & 10.03 & 0.56 & 1.59 & $1.34-1.89$ \\
\hline$\geq 400 \%$ & 97.9 & 0.29 & Reference & 6.55 & 0.40 & 1.00 & Reference \\
\hline
\end{tabular}


TABle 4: Continued.

\begin{tabular}{|c|c|c|c|c|c|c|c|}
\hline \multirow[b]{2}{*}{ Covariate } & \multicolumn{3}{|c|}{ Behavioral problems index ${ }^{1}$} & \multicolumn{4}{|c|}{ Serious behavioral problem ${ }^{2}$} \\
\hline & Mean & SE & $P$ value & $\begin{array}{c}\text { Weighted } \\
\text { prevalence } \\
(\%)^{3}\end{array}$ & SE & $\begin{array}{c}\text { Unadjusted } \\
\text { OR }\end{array}$ & $\begin{array}{c}95 \text {-percent } \\
\text { confidence } \\
\text { interval }\end{array}$ \\
\hline \multicolumn{8}{|l|}{ Perceived neighborhood safety } \\
\hline Unsafe & 106.1 & 0.72 & $<0.001$ & 19.89 & 1.24 & 2.12 & $1.79-2.51$ \\
\hline Safe & 100.0 & 0.23 & Reference & 10.48 & 0.34 & 1.00 & Reference \\
\hline \multicolumn{8}{|c|}{ Television watching (number of hours per day) } \\
\hline$<1$ & 97.7 & 0.42 & Reference & 8.10 & 0.67 & 1.00 & Reference \\
\hline 1 & 99.4 & 0.42 & 0.004 & 9.48 & 0.59 & 1.19 & $0.95-1.48$ \\
\hline 2 & 101.3 & 0.38 & $<0.001$ & 11.79 & 0.62 & 1.52 & $1.23-1.87$ \\
\hline$>2$ & 105.1 & 0.55 & $<0.001$ & 18.05 & 0.85 & 2.50 & $2.03-3.08$ \\
\hline \multicolumn{8}{|l|}{ Physical activity (number of days per week) } \\
\hline 0 & 107.8 & 0.94 & $<0.001$ & 22.90 & 1.43 & 3.06 & $2.54-3.68$ \\
\hline $1-2$ & 103.9 & 0.72 & $<0.001$ & 16.27 & 1.22 & 2.00 & $1.64-2.44$ \\
\hline $3-4$ & 100.7 & 0.39 & $<0.001$ & 10.91 & 0.65 & 1.26 & $1.07-1.48$ \\
\hline 5 or more & 98.8 & 0.28 & Reference & 8.84 & 0.39 & 1.00 & Reference \\
\hline \multicolumn{8}{|l|}{ Sports participation } \\
\hline Yes & 98.8 & 0.24 & Reference & 8.18 & 0.35 & 1.00 & Reference \\
\hline No & 103.8 & 0.41 & $<0.001$ & 16.88 & 0.64 & 2.28 & $2.01-2.59$ \\
\hline \multicolumn{8}{|c|}{$\begin{array}{l}\text { Sleep behavior (number of nights child getting } \\
\text { adequate sleep during past week) }\end{array}$} \\
\hline 0 & 112.0 & 1.56 & $<0.001$ & 26.69 & 2.34 & 3.52 & $2.74-4.53$ \\
\hline $1-4$ & 109.8 & 0.83 & $<0.001$ & 22.23 & 1.33 & 2.77 & $2.32-3.30$ \\
\hline $5-6$ & 102.8 & 0.39 & $<0.001$ & 11.51 & 0.65 & 1.26 & $1.08-1.47$ \\
\hline 7 & 98.1 & 0.26 & Reference & 9.36 & 0.40 & 1.00 & Reference \\
\hline \multicolumn{8}{|l|}{ BMI status of child } \\
\hline Normal weight (<85th percentile) & 99.9 & 0.28 & Reference & 10.37 & 0.41 & 1.00 & Reference \\
\hline Overweight ( 85 th to $<95$ th percentile) & 101.3 & 0.61 & 0.041 & 11.79 & 0.75 & 1.15 & $0.98-1.36$ \\
\hline Obese ( $\geq 95$ th percentile) & 103.2 & 0.52 & $<0.001$ & 14.94 & 0.86 & 1.52 & $1.30-1.78$ \\
\hline
\end{tabular}

${ }^{1}$ Higher scores on the index indicate higher levels of behavioral problems. ${ }^{2}$ This binary outcome variable was defined on the basis of whether or not the child had a BPI score $>90$ th percentile.

${ }^{3}$ The $\chi^{2}$ test for the overall association between each covariate and the prevalence of serious behavioral problems was statistically significant at $P<0.01$.

advantage notwithstanding many immigrant children appear to have a much higher unmet need for mental health services than native children, as reported in Table 3.

Besides the substantial effect of ethnic-immigrant status, we found that children and adolescents with higher levels of physical inactivity, TV viewing, and sleep problems had significantly higher levels of behavioral problems and a higher likelihood of experiencing serious behavioral problems [4]. The effects of obesity-related risk factors on children's behavioral problems remained significant, albeit somewhat reduced, after controlling for household socioeconomic and demographic characteristics. The substantial impact of household SES and perceived neighborhood safety on children's behavioral health is consistent with the findings of past research $[4-6,29]$.

We examined possible mechanisms through which ethnic-immigrant status and household socioeconomic factors might influence children's risks of experiencing behavioral problems. Increased TV viewing, lack of physical activity and sports participation, and sleep disruption were each independently related to BPI and SBP risk in children.
Assessment of the effects of these behavioral risk factors on children's mental health has received little attention in past research $[4,33]$. We are not aware of any research that looks at the impact of these characteristics in explaining behavioral health disparities among immigrant and nativeborn children.

Although household socioeconomic, demographic, and behavioral factors accounted for a substantial proportion of ethnic-immigrant disparities in behavioral health, ethnic-immigrant differentials in behavioral health remained marked. Adjustment for socioeconomic, demographic, and obesity-related factors reduced the magnitude of ethnicimmigrant disparities in SBP by $48.5 \%$ and in mean BPI by 37\% (Table 6). What might explain the residual differences?

Positive immigrant selectivity in health, education, skills, and ambition and higher levels of social support have been suggested as likely explanations for better health of immigrants [35-37]. More than $80 \%$ of immigrants to the United States come from Latin America and Asia [16], who appear to be a healthier group than those who remain in their countries of origin. Given the US immigration laws of the past four 
TABLE 5: Multivariate weighted least squares and logistic regressions showing the impact of ethnic-immigrant status and sociodemographic and obesity-related risk factors on behavioral problems among US children aged 6-17 years: the 2007 National Survey of Children's Health $(N=60,787)$.

\begin{tabular}{|c|c|c|c|c|c|}
\hline \multirow{2}{*}{ Covariate } & \multicolumn{3}{|c|}{ Behavioral problems index } & \multicolumn{2}{|c|}{ Serious behavioral problem } \\
\hline & Adjusted mean ${ }^{1}$ & SE & $P$ value & Adjusted odds ratio $^{2}$ & $95 \% \mathrm{CI}$ \\
\hline \multicolumn{6}{|l|}{ Age (years) } \\
\hline $6-9$ & 101.6 & 0.36 & Reference & 1.00 & Reference \\
\hline $10-11$ & 101.5 & 0.55 & 0.937 & 1.28 & $1.02-1.59$ \\
\hline $12-14$ & 101.0 & 0.42 & 0.309 & 1.25 & $1.05-1.50$ \\
\hline $15-17$ & 98.9 & 0.46 & $<0.001$ & 1.14 & $0.93-1.39$ \\
\hline \multicolumn{6}{|l|}{ Gender } \\
\hline Male & 102.1 & 0.31 & $<0.001$ & 1.50 & $1.31-1.72$ \\
\hline Female & 99.2 & 0.31 & Reference & 1.00 & Reference \\
\hline \multicolumn{6}{|l|}{ Ethnic-immigrant status } \\
\hline Hispanic children of immigrant parents & 97.3 & 1.03 & 0.149 & 2.57 & $1.22-5.40$ \\
\hline Hispanic children of US-born parents & 100.4 & 1.08 & $<0.001$ & 2.99 & $1.43-6.29$ \\
\hline White children of immigrant parents & 101.7 & 0.94 & $<0.001$ & 3.44 & $1.62-7.31$ \\
\hline White children of US-born parents & 102.0 & 0.27 & $<0.001$ & 3.14 & $1.57-6.25$ \\
\hline Black children of immigrant parents & 98.6 & 2.12 & 0.141 & 3.55 & $1.37-9.23$ \\
\hline Black children of US-born parents & 98.6 & 0.69 & 0.010 & 2.83 & $1.40-5.74$ \\
\hline Asian children of immigrant parents & 95.1 & 1.17 & Reference & 1.00 & Reference \\
\hline Asian children of US-born parents & 101.7 & 2.40 & 0.013 & 3.12 & $1.04-9.36$ \\
\hline Other children of immigrant parents & 97.8 & 1.97 & 0.236 & 2.87 & $1.22-6.75$ \\
\hline Other children of US-born parents & 102.8 & 0.81 & $<0.001$ & 3.67 & $1.78-7.59$ \\
\hline \multicolumn{6}{|l|}{ Mother's duration of residence in the US (years) } \\
\hline$<5$ & 97.8 & 2.04 & 0.070 & 0.46 & $0.23-0.95$ \\
\hline $5-9$ & 97.7 & 1.50 & 0.014 & 0.85 & $0.49-1.46$ \\
\hline $10-14$ & 96.4 & 1.81 & 0.006 & 0.76 & $0.41-1.42$ \\
\hline $15+$ & 99.0 & 0.88 & 0.009 & 0.80 & $0.58-1.10$ \\
\hline US born & 101.5 & 0.30 & Reference & 1.00 & Reference \\
\hline \multicolumn{6}{|l|}{ Child's race/ethnicity } \\
\hline Non-Hispanic white & 101.6 & 0.29 & 0.017 & 1.78 & $0.99-3.21$ \\
\hline Non-Hispanic black & 98.3 & 0.64 & 0.909 & 1.64 & $0.90-3.01$ \\
\hline Hispanic & 100.0 & 0.80 & 0.263 & 1.78 & $1.00-3.18$ \\
\hline American Indian/Alaska native & 100.6 & 1.54 & 0.286 & 1.66 & $0.81-3.42$ \\
\hline Asian & 98.5 & 1.22 & Reference & 1.00 & Reference \\
\hline Hawaiian/Pacific Islander & 100.8 & 2.25 & 0.369 & 2.80 & $1.18-6.66$ \\
\hline Non-Hispanic mixed race & 102.2 & 0.97 & 0.019 & 2.15 & $1.14-4.05$ \\
\hline Other & 102.3 & 2.24 & 0.139 & 1.81 & $0.54-6.04$ \\
\hline \multicolumn{6}{|l|}{ Household composition } \\
\hline Two-parent biological & 99.2 & 0.31 & Reference & 1.00 & Reference \\
\hline Two-parent stepfamily & 104.6 & 0.72 & $<0.001$ & 1.99 & $1.60-2.46$ \\
\hline Single mother & 102.9 & 0.56 & $<0.001$ & 1.61 & $1.33-1.95$ \\
\hline Other family type & 102.3 & 0.83 & $<0.001$ & 1.79 & $1.43-2.24$ \\
\hline \multicolumn{6}{|c|}{$\begin{array}{l}\text { Household poverty status (ratio of family income to poverty } \\
\text { threshold) }\end{array}$} \\
\hline$<100 \%$ & 103.6 & 0.67 & $<0.001$ & 2.07 & $1.64-2.62$ \\
\hline $100-199 \%$ & 101.1 & 0.58 & 0.01 & 1.63 & $1.31-2.03$ \\
\hline $200-399 \%$ & 100.3 & 0.38 & 0.044 & 1.27 & $1.05-1.52$ \\
\hline$\geq 400 \%$ & 99.3 & 0.35 & Reference & 1.00 & Reference \\
\hline \multicolumn{6}{|l|}{ Perceived neighborhood safety } \\
\hline Unsafe & 103.9 & 0.71 & $<0.001$ & 1.47 & $1.20-1.79$ \\
\hline Safe & 100.2 & 0.24 & Reference & 1.00 & Reference \\
\hline
\end{tabular}


TABle 5: Continued.

\begin{tabular}{|c|c|c|c|c|c|}
\hline \multirow{2}{*}{ Covariate } & \multicolumn{3}{|c|}{ Behavioral problems index } & \multicolumn{2}{|c|}{ Serious behavioral problem } \\
\hline & Adjusted mean ${ }^{1}$ & SE & $P$ value & Adjusted odds ratio $^{2}$ & $95 \%$ CI \\
\hline \multicolumn{6}{|c|}{ Television watching (number of hours per day) } \\
\hline$<1$ & 98.7 & 0.42 & Reference & 1.00 & Reference \\
\hline 1 & 99.9 & 0.42 & 0.048 & 1.11 & $0.88-1.39$ \\
\hline 2 & 101.1 & 0.37 & $<0.001$ & 1.30 & $1.05-1.62$ \\
\hline$>2$ & 103.3 & 0.52 & $<0.001$ & 1.65 & $1.32-2.05$ \\
\hline \multicolumn{6}{|c|}{ Physical activity (number of days per week) } \\
\hline 0 & 106.0 & 0.92 & $<0.001$ & 2.01 & $1.63-2.49$ \\
\hline $1-2$ & 103.0 & 0.66 & $<0.001$ & 1.56 & $1.27-1.91$ \\
\hline $3-4$ & 101.1 & 0.39 & $<0.001$ & 1.23 & $1.04-1.47$ \\
\hline 5 or more & 99.0 & 0.31 & Reference & 1.00 & Reference \\
\hline \multicolumn{6}{|l|}{ Sports participation } \\
\hline Yes & 99.6 & 0.26 & Reference & 1.00 & Reference \\
\hline No & 102.3 & 0.41 & $<0.001$ & 1.64 & $1.41-1.90$ \\
\hline \multicolumn{6}{|c|}{$\begin{array}{l}\text { Sleep behavior (number of nights child getting adequate sleep } \\
\text { during past week) }\end{array}$} \\
\hline 0 & 110.8 & 1.54 & $<0.001$ & 3.23 & $2.47-4.22$ \\
\hline $1-4$ & 109.3 & 0.84 & $<0.001$ & 2.77 & $2.28-3.37$ \\
\hline $5-6$ & 103.1 & 0.39 & $<0.001$ & 1.39 & $1.18-1.64$ \\
\hline 7 & 98.0 & 0.26 & Reference & 1.00 & Reference \\
\hline \multicolumn{6}{|l|}{ BMI status of child } \\
\hline Normal weight & 100.5 & 0.30 & Reference & 1.00 & Reference \\
\hline Overweight & 101.2 & 0.58 & 0.293 & 1.04 & $0.87-1.24$ \\
\hline Obese & 101.4 & 0.50 & 0.139 & 1.14 & $0.95-1.36$ \\
\hline
\end{tabular}

${ }^{1}$ Adjusted by multivariate least squares regression for child's age, gender, ethnic-immigrant status (or race/ethnicity and mother's duration of residence in the US), household composition, household poverty status, perceived neighborhood safety, TV watching, physical activity, sports participation, sleep behavior, and overweight/obesity status.

${ }^{2}$ Adjusted by multivariate logistic regression for the same covariates as in the least squares model.

decades, most legal immigrants today are chosen rather than randomly self-selected based primarily on their skill criteria [35-37].

Several other factors that we did not consider might account for the observed ethnic-immigrant differentials in behavioral health. They include factors such as parental physical and mental health status, socioeconomic characteristics other than household income, social environmental factors, including neighborhood social and built environments, ethnic and cultural differences in interpretation or understanding of survey questions including those related to perceived childhood behaviors, and interviewer bias [4]. Future research is needed to examine the role of these factors in explaining behavioral health disparities reported here.

A major strength of our study concerns estimating the effects of a number of obesity-related risk factors and detailed ethnic-immigrant status on children's behavioral problems-which have been studied either little or not at all. The construction of a highly valid and reliable behavioral problems index for various racial/ethnic and immigrant groups and of a binary variable capturing serious behavioral problems in US children should be seen as an important contribution to the behavioral health literature. Measuring various types of child and parental health effects of childhood behavioral problems for both immigrants and natives is a unique and novel contribution. The other strengths of our study include the large sample size, the generalizability of our findings, and examination of whether behavioral health effects of obesity-related factors and household SES vary by nativity/immigrant status.

This study has limitations. First, behavioral problems in our study were based on parental reports and might not accurately reflect the true prevalence, particularly among older adolescents or among those primarily experiencing internalizing symptoms [4]. Second, our study lacked data on other immigration-related variables such as citizenship, naturalization, and legal status that may affect the health and socioeconomic status of both parents and children in immigrant families [30, 31, 35-37]. Third, the NSCH lacks ethnic detail. The survey does not identify specific immigrant Hispanic and Asian subgroups such as Mexicans, Cubans, Puerto Ricans, Central and South Americans, Chinese, Asian Indians, Filipinos, Japanese, Koreans, and Vietnamese. These groups are quite heterogeneous in their socioeconomic, cultural, and immigration characteristics and are, therefore, expected to differ in their health and behavioral outcomes as well [35]. Fourth, immigrant parents in socioeconomically disadvantaged families may have downgraded the severity or 


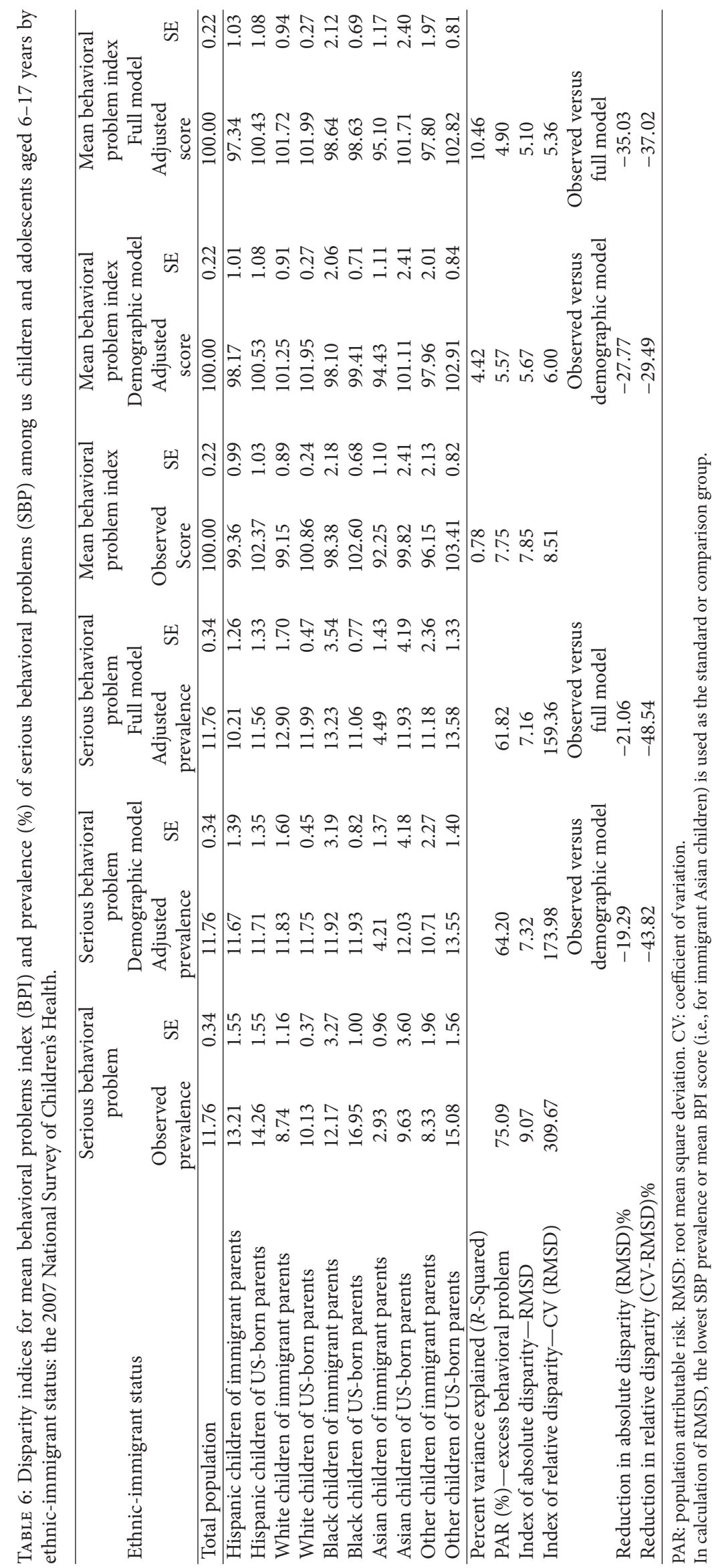


frequency of behavioral problems among their children, thus creating an "optimistic" bias [4]. Fifth, because of the crosssectional nature of the $\mathrm{NSCH}$, causal inferences about the relationship between social and obesity-related risk factors and childhood behavioral problems cannot be drawn [4].

The evidence presented here suggests that ethnicimmigrant status, obesity-related risk factors, and adverse socioeconomic conditions are significantly associated with increased risk of behavioral problems in children. Since obesity-related behaviors are amenable to change through social and public policy interventions, these behaviors along with household socioeconomic conditions remain crucial in determining children's emotional and behavioral health. Since the social environments, including household SES and neighborhood conditions, are the underlying determinants of obesity-related risk factors [21-23], social policy measures aimed at improving the broader social environments are vital to improving the overall health of immigrant and native children in general and their mental health in particular. Achieving health equity continues to be one of the most important overarching goals for the United States [38]; however, the existence of substantial socioeconomic inequalities among ethnic-immigrant groups, as shown in this study, poses a tremendous challenge to achieving improvements in the mental health of children in several immigrant and native-born groups.

\section{Consent}

No IRB approval was required for this study, which is based on the secondary analysis of a public-use federal database.

\section{Conflicts of Interests}

The authors declare that they have no conflict of interests.

\section{Disclaimer}

The views expressed are the authors' and not necessarily those of the Health Resources and Services Administration or the US Department of Health and Human Services.

\section{References}

[1] Health Resources and Services Administration and Maternal and Child Health Bureau, The Mental and Emotional WellBeing of Children: A Portrait of States and the Nation 2007, U.S. Department of Health and Human Services, Rockville, Md, USA.

[2] G. A. Simpson, B. Bloom, R. A. Cohen, S. Blumberg, and K. H. Bourdon, "U.S. children with emotional and behavioral difficulties: data from the 2001, 2002, and 2003 National Health Interview Surveys," Advance Data, no. 360, pp. 1-13, 2005.

[3] Y. Xue, T. Leventhal, J. Brooks-Gunn, and F. J. Earls, "Neighborhood residence and mental health problems of 5- to 11-yearolds," Archives of General Psychiatry, vol. 62, no. 5, pp. 554-563, 2005.

[4] G. K. Singh and M. Ghandour, "Impact of neighborhood social conditions and household socioeconomic status on behavioral problems among US children," Maternal and Child Health Journal, vol. 16, pp. S158-S169, 2012.

[5] A. R. Pebley and N. Sastry, "Neighborhoods, poverty, and children's well-being," in Social Inequality, K. M. Neckerman, Ed., pp. 119-144, Russell Sage Foundation, New York, NY, USA, 2004.

[6] T. Leventhal and J. Brooks-Gunn, "The neighborhoods they live in: the effects of neighborhood residence on child and adolescent outcomes," Psychological Bulletin, vol. 126, no. 2, pp. 309-337, 2000.

[7] E. B. Winslow and D. S. Shaw, "Impact of neighborhood disadvantage on overt behavior problems during early childhood," Aggressive Behavior, vol. 33, no. 3, pp. 207-219, 2007.

[8] J. L. Moren-Cross, D. R. Wright, M. LaGory, and R. G. Lanzi, "Perceived neighborhood characteristics and problem behavior among disadvantaged children," Child Psychiatry and Human Development, vol. 36, no. 3, pp. 273-294, 2006.

[9] J. Schneiders, M. Drukker, J. van der Ende, F. C. Verhulst, J. van Os, and N. A. Nicolson, "Neighbourhood socioeconomic disadvantage and behavioural problems from late childhood into early adolescence," Journal of Epidemiology and Community Health, vol. 57, no. 9, pp. 699-703, 2003.

[10] W. A. M. Vollebergh, M. ten Have, M. Dekovic et al., "Mental health in immigrant children in the Netherlands," Social Psychiatry and Psychiatric Epidemiology, vol. 40, no. 6, pp. 489-496, 2005.

[11] M. T. Kantomaa, T. H. Tammelin, H. E. Ebeling, and A. M. Taanila, "Emotional and behavioral problems in relation to physical activity in youth," Medicine and Science in Sports and Exercise, vol. 40, no. 10, pp. 1749-1756, 2008.

[12] L. C. Davies and R. S. McKelvey, "Emotional and behavioural problems and competencies among immigrant and nonimmigrant adolescents," Australian and New Zealand Journal of Psychiatry, vol. 32, no. 5, pp. 658-665, 1998.

[13] M. Beiser, F. Hou, I. Hyman, and M. Tousignant, "Poverty, family process, and the mental health of immigrant children in Canada," American Journal of Public Health, vol. 92, no. 2, pp. 220-227, 2002.

[14] M. Tienda and R. Haskins, "Immigrant children: introducing the issue," Future of Children, vol. 21, no. 1, pp. 3-18, 2011.

[15] L. P. Walters and E. N. Trevelyan, "The newly arrived foreignborn population of the United States: 2010," American Community Survey Briefs, US Census Bureau, Washington, DC, USA, 2011.

[16] E. M. Grieco and E. N. Trevelyan, "Place of birth of the foreignborn population: 2009," American Community Survey Briefs, US Census Bureau, Washington, DC, USA, 2010.

[17] E. M. Grieco, "Race and hispanic origin of the foreign-born population in the United States: 2007," American Community Survey Briefs, US Census Bureau, Washington, DC, USA, 2010.

[18] L. J. Larsen, "The foreign-born population in the United States: 2003," Current Population Reports, US Census Bureau, Washington, DC, USA, 2003.

[19] US Census Bureau, The 2011 American Community Survey, US Census Bureau, Washington, DC, USA, 2012.

[20] Federal Interagency Forum on Child and Family Statistics, America'S Children: Key National Indicators of Well-Being, 2012, US Government Printing Office, Washington, DC, USA, 2012.

[21] G. K. Singh, M. Siahpush, and M. D. Kogan, "Rising social inequalities in US childhood obesity, 2003-2007," Annals of Epidemiology, vol. 20, no. 1, pp. 40-52, 2010. 
[22] G. K. Singh and M. D. Kogan, "Contemporary racial/ethnic and socioeconomic patterns in US childhood obesity," in Global Perspectives on Childhood Obesity: Current Status, Consequences and Prevention, D. Bagchi, Ed., pp. 71-85, Academic Press, San Diego, Calif, USA, 2010.

[23] G. K. Singh, M. Siahpush, and M. D. Kogan, "Neighborhood socioeconomic conditions, built environments, and childhood obesity," Health Affairs, vol. 29, no. 3, pp. 503-512, 2010.

[24] National Center for Health Statistics, The National Survey of Children'S Health (NSCH), 2007, US Department of Health and Human Services, Hyattsville, Md, USA, 2009.

[25] Health Resources and Services Administration and Maternal and Child Health Bureau, the National Survey of Children'S Health 2007: The Health and Well-Being of Children, A Portrait of StateS and the Nation, US Department of Health and Human Services, Rockville, Md, USA, 2009.

[26] S. J. Blumberg, E. B. Foster, A. M. Frasier et al., "Design and operation of the National Survey of Children's Health, 2007," Vital Health Stat, vol. 1, no. 55, pp. 1-149, 2012.

[27] J. L. Peterson and N. Zill, "Marital disruption, parent-child relationships, and behavior problems in children," Journal of Marriage and the Family, vol. 48, no. 2, pp. 295-307, 1986.

[28] S. Hofferth, P. E. Davis-Kean, J. Davis, and J. Finkelstein, "The child development supplement to the panel study of income dynamics," in 1997 Users Guide, Assessments and Scales, chapter 6, Institute for Social Research, University of Michigan, 1999.

[29] G. A. Simpson and M. G. Fowler, "Geographic mobility and children's emotional/behavioral adjustment and school functioning," Pediatrics, vol. 93, no. 2, pp. 303-309, 1994.

[30] G. K. Singh, M. D. Kogan, and S. M. Yu, "Disparities in obesity and overweight prevalence among us immigrant children and adolescents by generational status," Journal of Community Health, vol. 34, no. 4, pp. 271-281, 2009.

[31] G. K. Singh, S. M. Yu, M. Siahpush, and M. D. Kogan, "High levels of physical inactivity and sedentary behaviors among US immigrant children and adolescents," Archives of Pediatrics and Adolescent Medicine, vol. 162, no. 8, pp. 756-763, 2008.

[32] E. J. Paavonen, K. Räikkönen, J. Lahti et al., "Short sleep duration and behavioral symptoms of attention-deficit/ hyperactivity disorder in healthy 7 - to 8-year-old children," Pediatrics, vol. 123, no. 5, pp. e857-e864, 2009.

[33] A. Smaldone, J. C. Honig, and M. W. Byrne, "Sleepless in America: Inadequate sleep and relationships to health and wellbeing of our nation's children," Pediatrics, vol. 119, supplement 1, pp. S29-S37, 2007.

[34] SUDAAN, Software For the Statistical Analysis of Correlated Data, Release 10. 0. 1, Research Triangle Park, NC: Research Triangle Institute, 2009.

[35] G. K. Singh and R. A. Hiatt, "Trends and disparities in socioeconomic and behavioural characteristics, life expectancy, and cause-specific mortality of native-born and foreign-born populations in the United States, 1979-2003," International Journal of Epidemiology, vol. 35, no. 4, pp. 903-919, 2006.

[36] G. K. Singh, M. Siahpush, R. A. Hiatt, and L. R. Timsina, "Dramatic increases in obesity and overweight prevalence and body mass index among ethnic-immigrant and social class groups in the United States, 1976-2008," Journal of Community Health, vol. 36, no. 1, pp. 94-110, 2011.

[37] G. Jasso and M. Rosenzweig, The New Chosen People: Immigrants in the United States, Russell Sage Foundation, New York, USA, 1990.
[38] US Department of Health and Human Services, Healthy People 2020, http://www.healthypeople.gov/2020/default.aspx. 


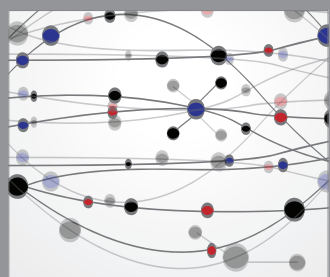

The Scientific World Journal
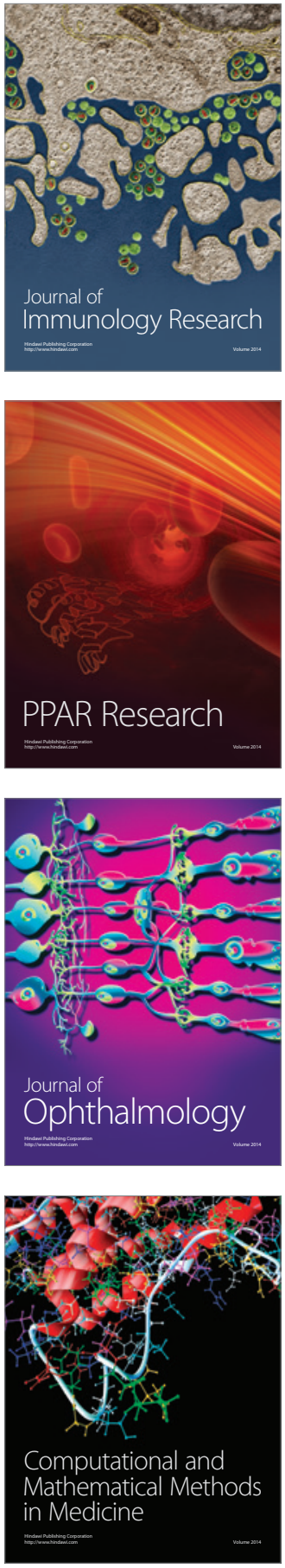

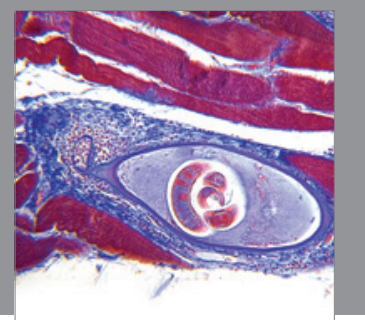

Gastroenterology

Research and Practice
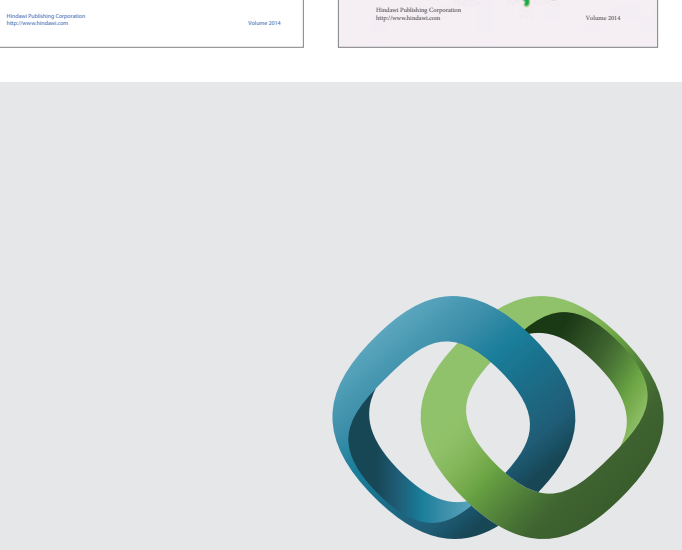

\section{Hindawi}

Submit your manuscripts at

http://www.hindawi.com
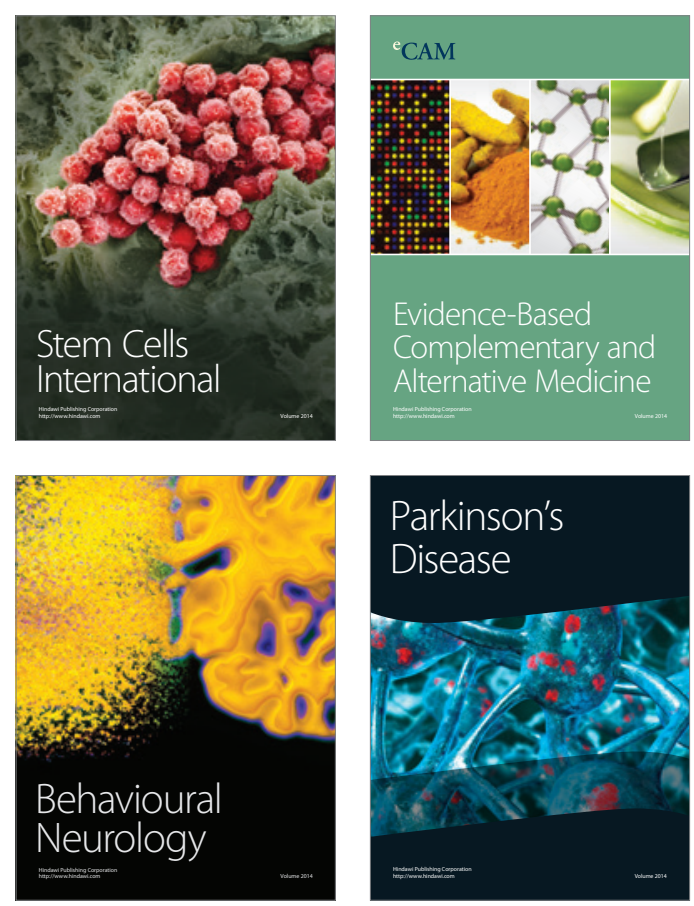

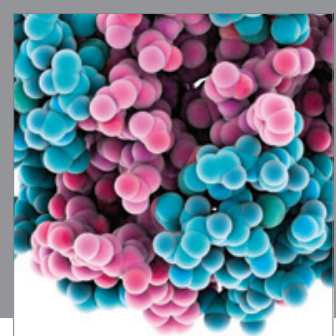

Journal of
Diabetes Research

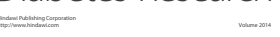

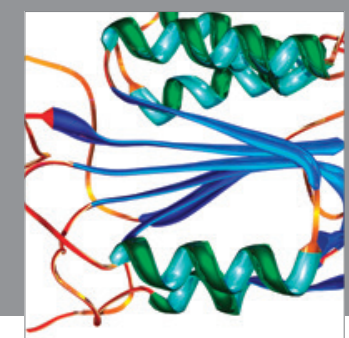

Disease Markers
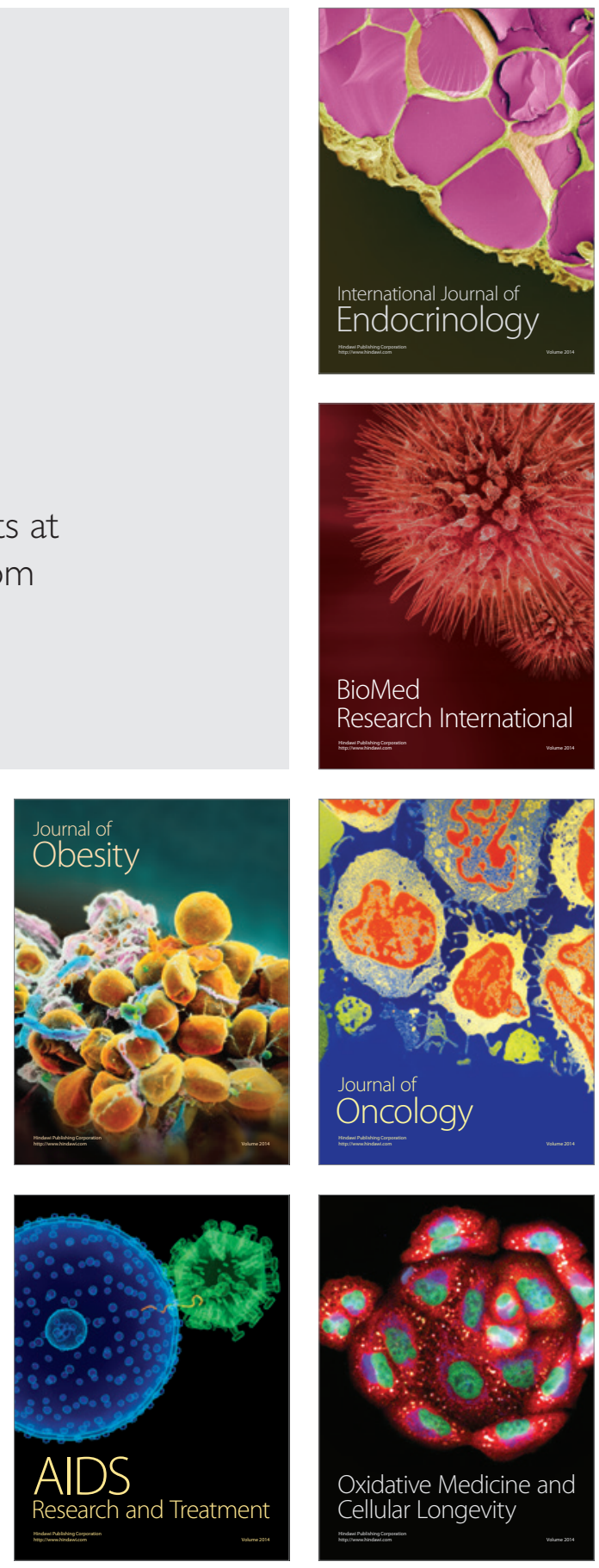